\title{
75 Deaths in asthmatics prescribed home nebulisers
}

\author{
M R SEARS, H H REA, J FENWICK, A J D GILLIES, P E HOLST, T V O'DONNELL, \\ R P G ROTHWELL
}

\begin{abstract}
The circumstances surrounding the deaths of 75 asthmatic patients who had been prescribed a domiciliary nebuliser driven by an air compressor pump for administration of high dose $\beta$ sympathomimetic drugs were investigated as part of the New Zealand national asthma mortality study. Death was judged unavoidable in 19 patients who seemed to have precipitous attacks despite apparently good long term management. Delays in seeking medical help because of overreliance on $\beta$ agonist delivered by nebuliser were evident in 12 cases and possible in a further 11 , but these represented only $8 \%$ of the 271 verified deaths from asthma in New Zealanders aged under $\mathbf{7 0}$ during the period. Evidence for direct toxicity of high dose $\beta$ agonist was not found. Nevertheless, the absence of serum potassium and theophylline concentrations and of electrocardiographic monitoring in the period immediately preceding death precluded firm conclusions whether arrhythmias might have occurred due to these factors rather than to hypoxia alone. In most patients prescribed domiciliary nebulisers death was associated with deficiencies in long term and short term care similar to those seen in patients without nebulisers.

Discretion in prescribing home nebulisers, greater use of other appropriate drugs, including adequate corticosteroids, and careful supervision and instruction of patients taking $\beta$ agonist by nebuliser should help to reduce the mortality from asthma.
\end{abstract}

\section{Introduction}

Because delivery of $\beta$ sympathomimetic drugs by nebuliser may induce greater bronchodilatation than use of a pressurised aerosol and may be as effective as administration by intermittent positive pressure ventilation, nebulisers powered by compressed oxygen have commonly been used in hospitals for severe asthma. ${ }^{1}$ Recently, nebulisers powered by electrical air compressor pumps or by oxygen have become popular outside hospital, ${ }^{2-4}$ especially for patients who have difficulty coordinating inhalation with actuation of a metered dose inhaler, or who are prone to severe attacks of asthma, or who have chronic poorly reversible asthma. Department of Medicine, University of Otago Medical School, PO Box 913,
Dunedin, New Zealand

M R SEARS, FRACP, associate professor

Green Lane Hospital, Auckland, New Zealand

H H REA, FRCPED, FRACP, respiratory physician

Department of Community Health and General Practice, University of Auckland, Auckland, New Zealand

J FENWICK, RN, nurse-interviewer

Princess Margaret Hospital, Christchurch, New Zealand

A J D GILLIES, FRACP, respiratory physician

Department of Medicine, Wellington Clinical School of Medicine, Wellington, New Zealand

PE HOLST, FRACP, associate professor

T V O'DONNELL, FRCP, FRACP, professor

Waikato Hospital, Hamilton, New Zealand

R P G ROTHWELL, FRCP, FRACP, respiratory physician

Correspondence to: Dr Sears.
The increased mortality from asthma in Britain, Australia, and New Zealand in 1966-8 was considered by many to be associated with undue reliance on bronchodilators, particularly high dose isoprenaline. ${ }^{5}$ In 1977 another increase in mortality from asthma occurred in young people in New Zealand but was not reported elsewhere. ${ }^{6}$ The combination of sustained release theophylline with inhaled $\beta$ sympathomimetic drugs was suggested as a possible cause, ${ }^{7}$ as was the increasing use of domiciliary nebulisers for delivery of high doses of $\beta$ sympathomimetics. ${ }^{4}$

A national mortality study by the asthma task force of the Medical Research Council of New Zealand between 1981 and 1983 yielded the largest series of deaths from asthma ever reported. ${ }^{8}$ Over a quarter of the 271 patients aged under 70 who died of asthma had been provided with a nebuliser for domiciliary use. We have reviewed these 75 patients and the circumstances of their death to see whether provision of home nebulisers might be associated with asthma mortality.

\section{Methods}

From 1 August 1981 to 31 July 1983 all deaths for which the coroner's report or part I of the death certificate contained the word "asthma" or "asthmatic" or "asthmaticus" were investigated. Methods of case finding, data collection, and verification have been reported.$^{89}$ Characteristics of the patients, their asthma, use of medications, and circumstances of death were determined by interviews with a close relative or friend and the patient's general practitioner and by review of hospital, police, and necropsy records where available. Using this information, a panel of experienced respiratory physicians reviewed each case and assessed severity of asthma, appropriateness of treatment, including reasons for providing a home nebuliser, the circumstances and management of the final attack, and whether the availability of a home nebuliser for administration of an inhaled $\beta$ sympathomimetic might have contributed to the fatal outcome.

\section{Results}

Of the 75 patients aged under 70 using home nebulisers, 40 were aged over 50 , six were children under 15 , and the remainder were evenly distributed between 15 and 50 . The duration of asthma before death ranged from two to 60 years, with no clustering. One patient had previously had mild asthma (no admissions or emergency visits to a doctor or limitation of activity), eight moderate asthma (activity limited, nocturnal attacks, or one or two emergency visits to a doctor in the last year), and 66 severe asthma (one or more admissions to hospital or three or more emergency visits to a doctor in the last year). Lifethreatening asthma resulting in loss of consciousness or hospital admission with documented hypercapnia had occurred in 27 patients (36\%). Asthma was fully reversible in 24 cases (32\%) and partially reversible in $44(59 \%)$ by objective testing or variability of symptoms; three patients had irreversible airflow obstruction, and information was not available in four cases.

Regular treatment prescribed for these 75 patients was regarded by the reviewing physicians as inadequate or very inadequate in 21 cases $(28 \%)$, adequate in $39(52 \%)$, and very good or maximal in $15(20 \%)$. All except one patient were taking a $\beta$ agonist by aerosol, and 20 also took oral sympathomimetics. Theophylline was prescribed for 60 patients $(80 \%)$, usually as a sustained release preparation. Rectal aminophylline suppositories were used by one patient. Serum theophylline measurements in the year before death were available for only 31 patients and none were in excess of the therapeutic range $(55-110 \mu \mathrm{mol} / \mathrm{l})$. Ipratropium bromide was prescribed for 36 patients, 23 by metered dose inhaler and 25 by nebuliser, both being used by 12 patients. Inhaled corticosteroid was prescribed for 54 patients $(72 \%)$, regular oral steroid for $41(55 \%)$, and both for $29(39 \%) ; 12(16 \%)$ used oral but not inhaled steroids. Only nine patients $(12 \%)$ took neither regular inhaled nor oral corticosteroids; two of these had received short courses of 
oral steroids previously. Compliance with treatment was judged by the panel on available evidence to be poor in $36 \%$ of cases, adequate in $35 \%$, and particularly good in $29 \%$.

Nebulisers were prescribed for 56 of the 75 patients on the grounds of severity of disease and previous lifethreatening attacks. In 19 cases, however, the reviewing panel could find little indication for use of a domiciliary nebuliser; rather, asthma could probably have been controlled by adequate aerosol bronchodilator and corticosteroid treatment. Nebulisers were prescribed for 31 patients by their general practitioner, for two by locum practitioners, and for 27 by hospital clinics or specialists; the source of recommendation for the remaining 15 was not clearly identified as general practitioner or specialist. Only one nebuliser was used without medical advice, when a mother used her child's machine in a severe attack. The duration of availability of the nebuliser was unknown in 29 cases, over one year in 24 , and less than one year in 22 , including seven patients for whom it had been prescribed within the two months before death. The most commonly used drugs were salbutamol (37 cases; $49 \%)$ and fenoterol (34 cases; $45 \%$ ). Ipratropium bromide was added to the $\beta$ agonist in 25 cases and cromoglycate in six. The use of diluent was not always recorded, nor was the exact dose of salbutamol or fenoterol delivered with each use, though where documented this ranged between $2 \cdot 5$ and $5.0 \mathrm{mg}$.

The nebuliser was used at least daily by 54 patients $(72 \%)$, probably daily by a further six, at least weekly by four, and less often by nine; frequency of use was unknown in two cases. Only 32 patients had a peak expiratory flow meter, 11 of whom used meters regularly in the month before death.

Medical supervision was provided by the general practitioner alone in 32 cases and by a specialist or clinic alone in six; combined care was evident in 37 cases. The quality of total medical care was considered by the panel to be poor in 27 cases $(36 \%)$, average in $40(53 \%)$, and particularly good in 8 (11\%).

\section{CIRCUMSTANCES OF DEATH}

There was no pattern of day of the week, month, or season of death. Most deaths $(55 ; 73 \%)$ occurred between 2000 and 0800 . During the final attack, which in some cases began 48 hours or more before death, 28 patients had seen or contacted their general practitioner, but only 14 were given additional corticosteroid treatment. Specific advice about the use of $\beta$ sympathomimetic by nebuliser was obtained by 11 patients during the final attack.

Of 66 patients whose domiciliary nebuliser was available to them during the final attack (figure), 44 were known to have used it at least once in the attack and 17 more than once, including 10 who took three or more treatments as the attack progressed. In the hour before death 36 patients used their nebuliser, five more than once, and 23 used the nebuliser within 10 minutes of death (table I). In almost no cases did use of the nebuliser bring any appreciable relief. Ten patients were inhaling nebulised $\beta$ agonist at the

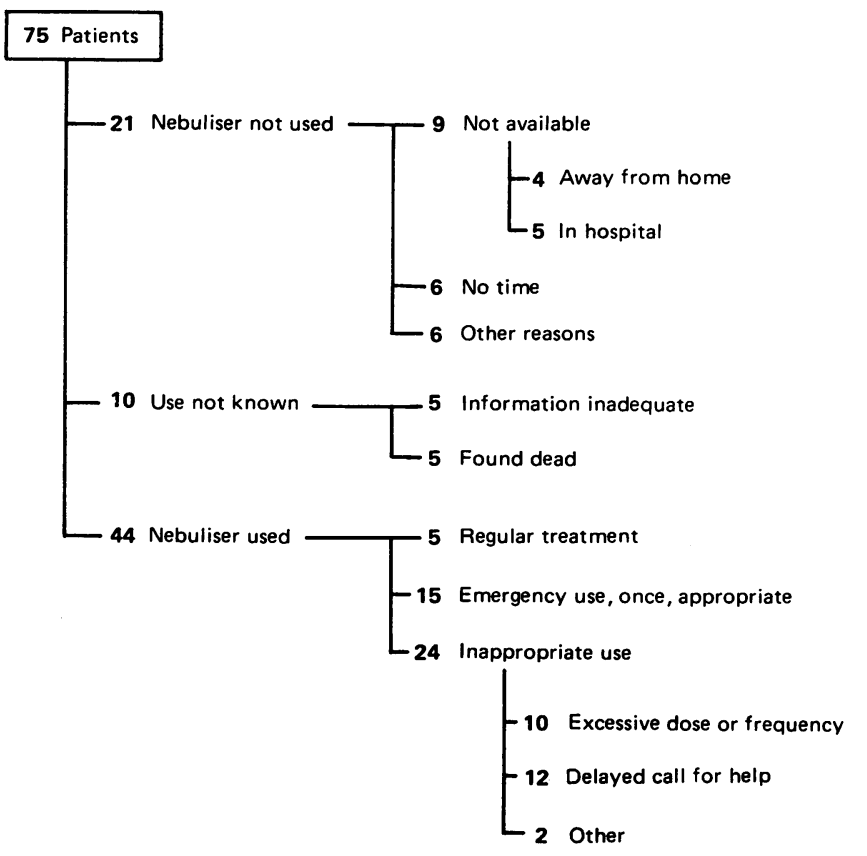

Use of domiciliary nebuliser during fatal attack in 75 patients.

onset of symptoms. While some of these precipitous attacks might have been prevented by better long term care or treated more quickly, possibly averting a fatal outcome, there were 19 patients whom the panel considered suffered unavoidable deaths despite appropriate treatment.

Case 1-A young woman had had several precipitous lifethreatening attacks despite regular treatment with $\beta$ agonist, inhaled corticosteroid, and theophylline in therapeutic doses. She suddenly developed severe wheezing and dyspnoea while staying with friends, having previously appeared quite well. Within three minutes of the onset she began using her nebuliser, but she died within five minutes of onset, having obtained no relief from nebulisation of about $1 \mathrm{mg}$ salbutamol.

\section{AVOIDABLE DEATHS (49 CASES)}

Two patterns of circumstances leading to deaths which could probably have been avoided were recognised. Frequently both patterns were seen in

TABLE I-Use of $\beta$ sympathomimetics by nebuliser in last attack, in last hour, and in last minutes before death. Figures are numbers of patients stratified by probable dose used

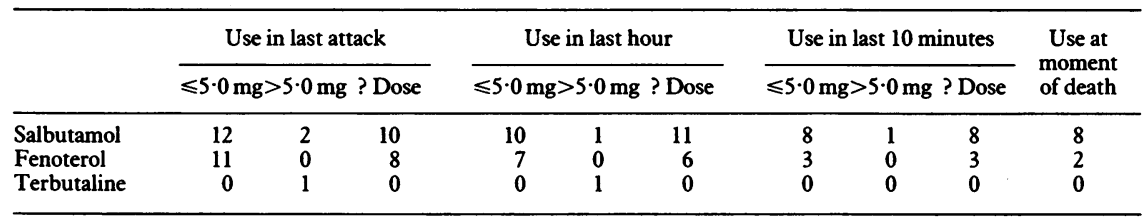

moment of death; all were in extremis before beginning the nebulised treatment and death appeared imminent. The panel considered that the availability of the domiciliary nebuliser clearly contributed to a delay in seeking medical help in 12 cases and possibly contributed in a further 11 . Equally often, however, the patient used the nebuliser appropriately, taking one emergency treatment and calling for help when it was ineffective.

Of the nine patients whose nebuliser was not available to them during the fatal episode (figure), four were away from home, four were in hospital, and one had walked into a hospital accident and emergency department to have her nebuliser checked.

\section{UNAVOIDABLE DEATHS (19 CASES)}

In 29 cases attacks seemed to be precipitous in onset with progression to death in less than three hours, and in 18 cases less than one hour, from the differing degrees in the same patient. The first pattern was associated primarily with inadequate long and short term care.

Case 2-A 29 year old woman with lifelong severe asthma was treated with oral and inhaled $\beta$ agonist and inhaled corticosteroids. She had not had any lung function assessment and appeared undertreated. A nebuliser was provided for severe attacks but no clear instructions given for its use. One month before death she received a short course of oral corticosteroid for severe asthma but follow up was not arranged. Exercise tolerance was persistently impaired. Some days before death she ran out of prednisone tablets. The evening before death she developed increased wheezing and dyspnoea and for six hours was restless but would not allow her husband to call her doctor. She then requested salbutamol by nebuliser but this failed to relieve her severe dyspnoea. She delayed further action for 20 minutes, then used the nebuliser a second time, again without benefit, became unconscious, and died minutes later.

The second pattern was associated with delay in seeking medical help in severe attacks, primarily because of overreliance on $\beta$ sympathomimetic by nebuliser. 
Case 3-A 45 year old man with lifelong severe asthma had previously been under specialist care and was receiving maintenance with inhaled and oral $\beta$ agonist, ipratropium bromide, theophylline, cromoglycate, and prednisone 10 mg daily but not inhaled corticosteroids. His asthma was only partially reversible on objective testing. While working at night he became increasingly wheezy and used his nebuliser to deliver at least $5 \mathrm{mg}$ fenoterol every one to one and a half hours for four hours without relief. After four doses his friends drove him to hospital, where he died on arrival, an event that he had predicted minutes before.

In the remaining seven patients the circumstances of death were such that the panel was in doubt whether death might have been avoided.

Overall the deficiencies in management identified in this group of patients with domiciliary nebulisers were similar to those found in the wider study of all deaths from asthma (table II). Nevertheless, fewer patients with nebulisers appeared to have "sudden deaths" (7\% compared with $22 \%$ overall) and fewer were found dead. Over $80 \%$ died during a witnessed attack of severe asthma unresponsive to usual treatment, which for 42 of 61 patients included high dose $\beta$ agonist by nebuliser.

TABLE II-Problems in long term care and management of final attack and mode of death in 75 patients with nebulisers compared with all 271 patients who died of asthmo in New Zealand over two years. Figures are numbers (percentages) of patients in each group

\begin{tabular}{lcc}
\hline & $\begin{array}{c}\text { All deaths } \\
\text { from asthma } \\
(\mathbf{n}=271)\end{array}$ & $\begin{array}{c}\text { Patients with } \\
\text { nebulisers } \\
(\mathbf{n}=75)\end{array}$ \\
\hline $\begin{array}{l}\text { Long term care: } \\
\text { Inadequate treatment and assessment }\end{array}$ & $103(38)$ & $27(36)$ \\
Poor patient compliance & $114(42)$ & $27(36)$ \\
Final attack: & $104(38)$ & $26(35)$ \\
Delay in seeking help & $18(7)$ & $1(1)$ \\
Inappropriate medical response & & \\
Mode of death: & $149(55)$ & $61(81)$ \\
Death in witnessed attack of severe asthma & $60(22)$ & $5(7)$ \\
"Sudden" death or collapse & $8(3)$ & $4(5)$ \\
Terminal respiratory failure & $8(3)$ & 0 \\
Died of complications & $46(17)$ & $5(7)$ \\
Found dead & & \\
\hline
\end{tabular}

\section{Discussion}

Other studies have identified poor appreciation of severity by patient and doctors and undertreatment, especially with corticosteroids, as common factors associated with mortality from asthma. ${ }^{10-12}$ The "epidemic" of deaths from asthma in New Zealand was investigated by a two year national survey of all deaths attributed to asthma and found to be a true increase not explained by inaccuracies in certification. ${ }^{9}$ While no single factor accounted for the excess deaths compared with other countries, ${ }^{813}$ there was concern that changes in management of asthma may have increased mortality. These changes were, firstly, the introduction of sustained release theophylline, ${ }^{7}$ and, secondly, the use of domiciliary nebulisers for administration of high dose $\beta$ agonists. ${ }^{4}$ The study of asthma mortality conducted in England two years before the New Zealand study did not contain any patients who used nebulisers. Indeed, the authors of that study recommended that to reduce mortality high dose $\beta$ agonist by nebuliser should be made available to patients prone to severe asthma. ${ }^{12}$ On the other hand, during a visit to New Zealand in 1982, Grant was concerned at the widespread use of nebulisers, particularly without supplemental oxygen, and suggested that this may have led to a repetition of the mid-1960s problem of increased mortality. ${ }^{4}$

The exact mechanism of death in asthma is not easily determined. Patients are invariably hypoxic during severe attacks, and this may be the most common primary cause of death. Fatal arrhythmias may be induced by hypoxia, but other causes have been postulated. Patients dying of asthma rarely have an electrocardiogram recorded at the time, and most have not had a very recent estimation of serum electrolyte or theophylline values. We found no case where the most recent serum theophylline concentration was above the therapeutic range, but measurements were not available for almost half the patients prescribed theophylline. The hypothesis that inhalation of high doses of $\beta$ agonist by nebuliser may cause death by inducing a fatal cardiac arrhythmia cannot be verified or negated by this study. We, however, sought to assess probabilities on the available evidence and linked death to use of a nebuliser if there was evidence for either a delay in seeking other medical help because of overreliance on the nebuliser or a sudden acceleration of deterioration during or after use of the nebuliser.

Delay in seeking help primarily because of overreliance on the nebuliser was evident in 12 of 75 cases and was possible in a further 11. Nevertheless, if all 23 were regarded as avoidable deaths attributable to inappropriate use of a nebuliser they still accounted for only $8 \%$ of all patients verified as dying of asthma in New Zealand over the two years. ${ }^{8}$ We cannot determine how many patients in that period were prevented from dying from acute severe asthma by the ready availability of high dose $\beta$ agonist delivered by home nebuliser. We can, however, identify among the other 196 patients who died (none of whom had a nebuliser) some who might have survived had they been treated with high dose inhaled $\beta$ sympathomimetic along with other appropriate treatment, including corticosteroids.

Among patients not already in extremis and in imminent danger of death we could find no clear evidence in any patient of a sudden deterioration during or after nebuliser use. Our assessment of probabilities was based on knowledge of the circumstances of death in 196 asthmatics who did not have a home nebuliser. ${ }^{813}$ In all cases where a nebuliser was used we concluded that the probability that inhalation of $\beta$ sympathomimetic by nebuliser contributed to death was lower than the probability that death would have occurred without treatment.

Almost equal numbers of patients with fatal asthma used fenoterol (45\%) and salbutamol (49\%) in their nebulisers, yet New Zealand sales of fenoterol for nebulisation (13800 units of $20 \mathrm{ml}$ ) were considerably less than sales of salbutamol (35000 units of 20 $\mathrm{ml}$; Intercontinental Medical Statistics, 1981). This discrepancy, which is not explained by chance $(t=3.649 ; \mathrm{p}<0.001)$, must be interpreted with caution. The relative frequency of use of these two drugs may differ between hospitals and the community, but partitioned sales figures are not available. Fenoterol was marketed after salbutamol, and patients with more severe asthma may have been transferred to the newer agent. Furthermore, physicians were strongly encouraged to prescribe fenoterol rather than salbutamol or other $\beta$ agonists if used in combination with nebulised ipratropium; of the 25 patients in this study prescribed nebulised ipratropium, 18 used fenoterol and seven salbutamol. These factors may all have contributed to the unexpectedly high frequency of use of nebulised fenoterol in cases of fatal asthma. That nebulised fenoterol is no more likely than salbutamol to be related directly to mortality is suggested by the relative frequencies with which the two drugs were known to be used in the 10 minutes before death (salbutamol 17 cases, fenoterol six) and at the moment of death (salbutamol eight cases, fenoterol two).

The study has highlighted several factors for concern regarding the domiciliary use of nebulisers. Firstly, nebulisers were provided unnecessarily to some patients who instead needed more adequate conventional treatment and greater efforts to educate and improve compliance with prescribed treatment. Some of these patients came to regard the nebuliser as first line treatment. Secondly, the most commonly used home nebuliser systems deliver the $\beta$ agonist in compressed air. Providing oxygen for nebuliser operation by patients with previous lifethreatening asthma has two advantagesprevention of possible worsening of hypoxia during drug delivery and availability of oxygen during a severe attack while awaiting medical help. Thirdly, some patients used high dose $\beta$ agonist by nebuliser repeatedly during the fatal attack and delayed seeking medical help. Patients must be instructed to seek attention when there is no substantial improvement (preferably measured objectively) after the first use of a nebuliser during a severe attack of asthma. Fourthly, patients whose asthma was judged severe enough to warrant provision of a nebuliser did not always receive adequate corticosteroid treatment. Some had complications of obesity and osteoporosis necessitating minimising their dose of prednisone, but this at times allowed their asthma to become very troublesome.

Nebulised $\beta$ agonist may be appropriate for some patients with severe asthma who have had a full trial of oral steroid treatment to assess reversibility and who show greater objective benefit from 
nebulised compared with aerosolised or dry powder $\beta$ agonists. There was a tendency evident in this study to provide patients with persistent asthma with nebulisers rather than take the time and effort needed to educate the patient adequately about effective management, proper technique of using metered dose inhalers, and self adjustment of oral corticosteroid regimens.

Grant's view that the overuse of domiciliary compressor driven nebulisers to deliver $\beta$ agonist without supplementary oxygen may have been a main reason for the excess mortality from asthma in New Zealand ${ }^{4}$ was widely publicised. Supervised use of nebulisers in patients who are also treated with other appropriate drugs can often produce substantial improvement, ${ }^{14}$ is though some patients may obtain equal benefit from use of cheaper and more portable aerosol spacers and chambers. Severe nocturnal asthma and "morning dips" can best be relieved by $\beta$ agonist. We believe that there is a place for the use of $\beta$ agonist by nebuliser in the chronic and emergency management of asthma but caution that some patients may regard these devices as more effective than they are in the management of lifethreatening attacks. Patients must be clearly instructed about action to be taken when use of the nebuliser does not bring appreciable relief confirmed with a peak flow meter reading. Such instruction may best be achieved by a written "crisis plan" which includes instructions about when to start or increase corticosteroids as well as when to seek medical help. Asthma may be rapidly fatal and undue delays must be avoided if mortality is to be reduced.

In summary, of 75 patients prescribed domiciliary nebulisers who subsequently died of asthma, at least $16 \%$ and possibly up to $30 \%$ delayed seeking help because of undue reliance on high dose $\beta$ agonists. While this accounted for at most only $8 \%$ of all deaths from asthma in a two year period and does not of itself explain the high mortality in New Zealand, adequate precautions in prescribing and supervising use of nebulisers should reduce these figures. Prompt medical attention and use of systemic corticosteroids when bronchodilator treatment is ineffective are essential to the management of severe asthma.

We thank the general practitioners and hospital medical staff and particularly the relatives of patients for their cooperation. The dedicated work of the interviewers who obtained so much detailed information about each patient is gratefully acknowledged. The study was supported by the Medical Research Council of New Zealand, the Maurice and Phyllis Paykel Trust, the New Zealand Asthma Society, and regional asthma societies.

\section{References}

1 Stainforth JN, Lewis RA, Tattersfield AE. Dosage and delivery of nebulised beta agonists in hospital. Thorax 1983;38:751-4.

2 Anonymous. The nebuliser epidemic [Editorial]. Lancet 1984;ii:789-90.

3 Laroche CM, Harries AVK, Newton RCF, Britten MG. Domiciliary nebulisers in asthma: a district survey. BrMed f 1985;290:1161-3.

4 Grant IWB. Asthma in New Zealand. BrMed f 1983;286:374-7.

5 Stolley PD, Schinnar R. Association between asthma mortality and isoproterenol aerosols: a review. Prev Med 1978;7:519-38.

6 Jackson RT, Beaglehole R, Rea HH, Sutherland DC. Mortality from asthma: a new epidemic in New Zealand. BrMed f 1982;285:771-4.

7 Wilson JD, Sutherland DC, Thomas AC. Has the change to beta-agonists combined with oral theophylline increased cases of fatal asthma? Lancet 1981;i:1235-7.

8 Sears MR, Rea HH, Beaglehole R, et al. Asthma mortality in New Zealand: a two year national study. NZ Med $\mathcal{J} 1985 ; 98: 271-5$.

9 Sears MR, Rea HH, de Boer G, et al. Accuracy of certification of deaths due to asthma: a national study. Am f Epidemiol 1986;124:1004-11.

10 McDonald JB, Seaton A, Williams DA. Asthma deaths in Cardiff 1963-74; 90 deaths outside hospital. BrMed f 1976; i: 1493-5.

11 Ormerod LP, Stableforth DE. Asthma mortality in Birmingham 1975-7: 53 deaths. Br Med $\mathcal{F}$ 1980;280:687-90.

12 British Thoracic Association. Deaths from asthma in two regions in England. $\mathrm{Br}$ Med $\mathcal{f}$ 1982;285:1251-5.

13 Sears MR, Rea HH, Rothwell RPG, et al. Asthma mortality: comparison between New Zealand and England. BrMed $\mathcal{F}$ 1986;293:1342-5.

14 McGivern DV, Ward M, Revill S, Sechiari A, Macfarlane J, Davies D. Home nebulisers in severe chronic asthma. Br $\mathcal{J}$ Dis Chest 1984;78:376-82.

15 Cochrane GM, Prior JG, Rees PJ. Home nebulisers for airflow limitation. Br Med J 1985;290 1608-9.

(Accepted 28 November 1986)

\section{SHORT REPORTS}

\section{Exceptional virilisation due to ovarian tumour and reversal after resection}

We report on a woman who had a virilising tumour and an exceptionally high testosterone concentration whose diagnosis was delayed by 11 years because of inappropriate biochemical tests.

\section{Case report}

A woman aged 35 presented with hirsutism, deepening voice, and amenorrhoea one year after the birth of her third child. She was referred to the local hospital, where the concentrations of her urinary 17 ketosteroids were measured. These were normal in most samples and marginally increased in others. An intravenous pyelogram was normal. Air insufflation studies to visualise the adrenal glands were technically unsatisfactory because of her obesity $(127 \mathrm{~kg})$. She was then lost to follow up.

Eleven years later she was referred again as her condition had worsened and she had become a recluse. The hirsutism was now so severe that she was shaving daily. She had considerable frontal balding, clitoromegaly, a deep voice, and an appreciable increase in muscle bulk. She was also obese. Serum biochemical tests showed: testosterone $310 \mathrm{nmol} / \mathrm{l}$ (normal female range $0 \cdot 5-2 \mathrm{nmol} / \mathrm{l}$, normal male range $10-30 \mathrm{nmol} / \mathrm{l}$ ), androstenedione 98 (normal $2-10) \mathrm{nmol} / \mathrm{l}$, dehydroepiandrosterone sulphate $19(2 \cdot 2-9 \cdot 8) \mu \mathrm{mol} / 1$, sex hormone binding globulin 31 (16119) $\mathrm{nmol} / \mathrm{l}$, and oestradiol (E2) 1385 (110-180 early follicular phase) pmol/1. Serum gonadotrophins were undetectable, and urinary free cortisol concentrations were normal. Computed axial tomography showed normal adrenal glands but a large mass in the left ovary, which was extending suprapubically but difficult to palpate on abdominal examination because of her considerable obesity. She was made to follow a strict diet and lost $16 \cdot 8 \mathrm{~kg}$. She then had a laparotomy and was found to have a solid benign ovarian tumour $8 \mathrm{~cm}$ in diameter, which was resected completely. The other ovary and the uterus were removed. Histological examination showed a mixed adrenal-Leydig cell tumour with no evidence of malignancy. Ovarian blood taken before operation showed concentrations of testosterone of $2700 \mathrm{nmol} / \mathrm{l}$, androstenedione $1200 \mathrm{nmol} / \mathrm{l}$, dehydroepiandrosterone sulphate $10.5 \mu \mathrm{mol} / \mathrm{l}$, and oestradiol $3670 \mathrm{pmol} / \mathrm{l}$.

Her postoperative recovery was dramatic. Within a few days she had started to shed vast quantities of hair into the bedclothes. Her serum testosterone concentration decreased during two days to $1 \mathrm{nmol} / \mathrm{l}$, and gonadotrophin concentrations increased progressively to the normal postmenopausal range. Two years after surgery she no longer needed to shave, and her scalp hair had grown dramatically (fig). She felt physically and mentally better and regained an interest in knitting and sewing. Her voice rose considerably to its previous pitch and timbre. She noticed no change in sex drive either before or after surgery. She received hormone replacement therapy with yearly implants of $50 \mathrm{mg}$ oestradiol.

\section{Comment}

This patient had an unusually high concentration of testosterone for either sex, and we have been unable to find any record of a man or woman achieving

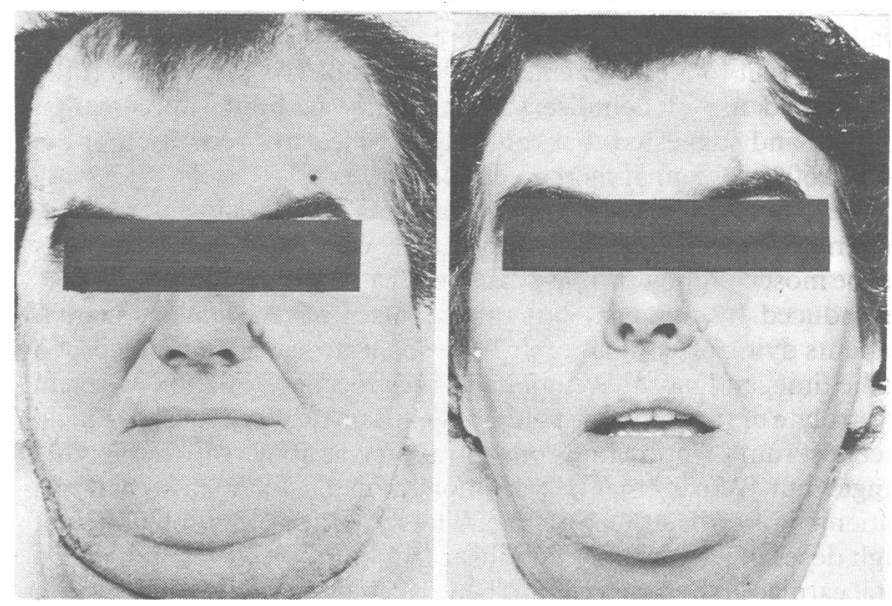

Appearance of patient before and six months after removal of virilising tumour. 